\title{
Jogos de linguagem, gramática emocional e formas de vida: uma etnografia do aprender brincando na natureza
}

Language games, emotional grammar and forms of life: an ethnographic study on learning through play in nature

Alessandra Rivero Hernandez ${ }^{*}$

* Pesquisadora independente - Porto Alegre, RS, Brasil riverohernandez@hotmail.com https://orcid.org/0000-0001-9710-0216

Ceres Víctora**

** Universidade Federal do Rio Grande do Sul - Porto Alegre, RS, Brasil ceresvictora@gmail.com https://orcid.org/0000-0001-9363-3883 


\title{
Resumo
}

O objetivo deste artigo é discutir a gramática emocional "alternativa" vinculada ao individualismo romântico. O debate fundamenta-se nos dados da pesquisa etnográfica realizada durante as Tardes no Verde. Trata-se de ocasiões em que crianças participam de brincadeiras e trilhas por entre a mata em um sítio em Porto Alegre. Embora essa gramática emocional não seja ensinada explicitamente, ela é aprendida a partir de jogos de linguagem que constituem uma forma de vida ecologicamente orientada. Argumenta-se que a gramática emocional "alternativa" é constituída por dois eixos. Um dos eixos diz respeito à lógica da escolha individual e da participação ativa, e rege emoções associadas ao engajamento ativo e criativo. Já o outro eixo se vincula à lógica da distinção entre natureza e cultura e rege sentimentos que informam como os distintos entes considerados como pertencentes ao domínio totalizante da natureza devem se relacionar entre si.

Palavras-chave: corpo; emoções; criança; formas de vida.

\begin{abstract}
This paper discusses the emotional grammar associated with learning an ecologically oriented way of life, based on ethnographic research carried out at an outdoor day camp called "Tardes no Verde" ("Green Afternoons"), where children participate in games, hike trails and engage in outdoor activities on the outskirts of Porto Alegre, Brazil. We argue that the emotional grammar is not explicitly taught by the teachers in charge, but is instead learned by the children from language games that conform to a way of life that is more conscious of nature. We suggest that this "alternative" emotional grammar is constructed according to two logics. The first concerns individual choice and active participation, and governs emotions associated with active and creative engagement. The second relies on the distinction between nature and culture and governs feelings that inform how different human and non-human entities, which belong to the totalizing domain of nature, relate to each other.
\end{abstract}

Keywords: body; emotions; child; forms of life. 
Este artigo faz parte de uma pesquisa maior na qual se investigaram diferentes práticas (vinculadas à gestação e ao parto, bem como aos cuidados e à educação de crianças) que constituem modos sensíveis de criação infantil. Trata-se de práticas que colocam em evidência os sentidos, que exaltam as experiências, as percepções, os afetos, as emoções, a intuição, a empatia, que se pautam na retórica da escolha e do engajamento individual, tendo no horizonte a afirmação do Indivíduo. ${ }^{1}$ Ainda, tais práticas não apenas são operadas com base nos sentidos, mas também animam e conformam uma sensibilidade romântica.

As emoções, como aponta Claudia Rezende (2012), podem ser compreendidas como elementos constitutivos de uma linguagem que discorre sobre as relações de alguém com os outros e com o mundo. Tomar os sentimentos como linguagem conduz à consideração de que a expressão de emoções apresenta regras socialmente definidas, em outras palavras, uma "gramática emocional" (Rezende; Coelho, 2010, p. 63) a partir das quais se torna possível a emergência dos sentimentos. A partir das reflexões do filósofo Ludwig Wittgenstein, consideramos a linguagem como atividade prática indissoluvelmente ligada à vida cotidiana dos falantes. Em uma segunda fase de suas reflexões, este autor argumenta que a linguagem ordinária antes do que uma descrição do real é uma forma de ação que conforma a experiência, constitui "formas de vida".

Nesse sentido, seu conceito de "jogos de linguagem" implica analisar as palavras nas situações em que são pronunciadas, uma vez que a linguagem adquire sentido em seus usos cotidianos (Cadavid, 2001; Ortega, 2008). Considerar que os sentimentos recobram sentido em seu contexto de uso leva a desnaturalizar as emoções tanto como uma essência universal invariável quanto como algo espontâneo e individual, dois modos decorrentes de lidar com as emoções no pensamento das sociedades ocidentais modernas (Rezende; Coelho, 2010).

1 No decorrer do artigo utiliza-se o recurso usual no campo da antropologia de iniciar com letra maiúscula quando se trata da categoria "Indivíduo", para assim diferenciá-la do indivíduo empírico. 
A respeito da abordagem de Wittgenstein sobre a linguagem, as ponderações do filósofo Stanley Cavell (1999, p. 177, tradução nossa) sobre o que é aprender uma palavra nessa perspectiva são muito esclarecedoras:

E podemos também dizer: quando dizes "eu amo meu amor", a criança aprende o significado da palavra "amor" e o que é o amor. Isso (aquilo que fizeres), será o amor no mundo da criança; e se isso está mesclado de ressentimento e intimidação, então o amor é uma mescla de ressentimento e intimidação, e quando o amor for procurado, isso [ressentimento e intimidação] é o que será o buscado. Quando dizes "te levarei a passear amanhã, prometo" a criança começa a aprender o que a duração temporal é, e o que confiar é, e o que fizeres mostrará que confiar vale a pena. Quando dizes "coloca tua blusa", a criança aprende o que as ordens são, o que a autoridade é, e se dar ordens é algo que produz ansiedade em ti, então as autoridades são ansiosas, a autoridade mesma é insegura.

Evidentemente a pessoa, ao crescer, aprenderá outras coisas sobre esses conceitos e "objetos" também. Estes irão crescendo gradualmente conforme o mundo da criança cresce. Mas tudo o que ele ou ela sabe sobre estes é o que tenha aprendido, e tudo o que eles tenham aprendido será parte do que são.

O presente texto investiga qual a gramática emocional associada à afirmação do Indivíduo romântico. Em seus trabalhos, Dumont $(1970,1985)$ aborda o holismo e o individualismo como duas configurações de valores que têm como princípios a hierarquia, na primeira, e a liberdade e a igualdade, na segunda. Sua análise versa sobre o individualismo quantitativo, relacionado historicamente aos ideais iluministas, e no qual o acento é posto no princípio da igualdade. Entretanto, cabe chamar a atenção para a existência do individualismo qualitativo, ou também nomeado de vertente psicológica, o qual teve sua origem no Romantismo e coloca ênfase na singularidade das qualidades pessoais, assim como na totalidade, na diferença e na sensibilidade, entre outros aspectos (Duarte, 2004).

Recorrendo a um termo bastante reiterado no campo empírico dessa pesquisa, poder-se-ia dizer que tal gramática emocional constitui-se como "alternativa". Isso porque os jogos de linguagem vigentes evocam uma experiência contracultural, que se vincula ao desejo de um retorno ao natural e 
a uma unidade perdida (seja com o universo, a natureza ou a coletividade humana), bem como ao sentimento anticapitalista como contrapontos aos males da cultura e da civilização (Carvalho, 2001). Embora essa gramática emocional não seja propriamente ensinada (uma vez que não costuma ser formulada explicitamente), ela é aprendida a partir dos jogos de linguagem particulares que constituem uma forma de vida específica. Certamente, esse processo de aprendizagem não ocorre apenas nos primeiros anos de vida, mas esse período representa uma oportunidade frutífera para compreender essa gramática emocional. Ainda mais tendo em vista a concepção de educação de crianças em jogo.

A fim de contextualizar as atividades educativas descritas neste trabalho, pode-se dizer minimamente que as mesmas se constituem como a práxis de diversas propostas de educação que têm em comum a crítica à escola moderna, a qual consideram operar um processo de transmissão de conhecimentos enquanto conteúdos mentais em que o sujeito é tomado como produto da cultura e da sociedade. Em contraponto a uma concepção cartesiana do processo educativo, as propostas em foco promovem uma "educação engajada", termo que designamos para fazer referência a esse conjunto variado de práticas educativas que concebem a aprendizagem como um processo que ocorre a partir do envolvimento ativo da criança com o ambiente. Nesse sentido, a aprendizagem é um fenômeno que se dá através da experimentação, do movimento, do brincar. Trata-se desse modo de uma aprendizagem que evoca o corpo no mundo, os sentidos e os afetos.

Nessa abordagem, o papel de quem educa não é, portanto, fazer a criança aprender, e sim "aprender a aprender", ou deuteroaprendizagem, termo usado por Gregory Bateson (1991, p. 177, 250, tradução nossa) para aludir o "aprender a receber sinais" e a "aquisição de informações sobre os padrões de contingência dos contextos" de aprendizagem. Ainda, essas práticas buscam o desenvolvimento de autonomia enquanto condição que não pode ser ensinada, mas sim aprendida pela criança a partir das relações com o ambiente e vivências cotidianas.

Embora o trabalho de Louis Dumont sobre o individualismo seja um aporte teórico relevante neste texto, sua análise se centra no sistema de ideias e valores vigente nas sociedades modernas ocidentais, ou seja, na representação do Indivíduo autônomo e independente. O presente artigo, sem recair na alegação 
da existência do Indivíduo, parte do princípio de que a percepção de si e dos outros como Indivíduos é conformada na ação, em meio a práticas, discursos, conhecimentos e eventos. Nesse deslocamento analítico, recorremos a autores que nos permitem abordar o tema a partir dessa perspectiva, como é o caso de Wittgenstein (que toma a linguagem ordinária enquanto uma forma de ação que conforma a experiência), bem como outros autores que tampouco se centram na questão do Indivíduo, mas iniciam suas análises pelas práticas cotidianas, para pensarmos como estas são capazes de engendrar valores, percepções e sensibilidades.

O debate que se segue fundamenta-se nos dados da pesquisa etnográfica realizada de agosto de 2014 a maio de 2015 durante as ocasiões denominadas Tardes no Verde, em que crianças de 3 a 14 anos de idade realizam, em dois turnos da semana, atividades lúdicas em um local considerado, em termos nativos, como "terapêutico" e "mais próximo dos ritmos da natureza". Durante as Tardes no Verde, as crianças, como dizem educadores e pais, brincam "livres" em um espaço repleto de árvores, riachos, hortas, insetos, brinquedos e objetos singelos, confeccionados em materiais como madeira, lã e sucata.

A discussão também se baseia no trabalho de campo realizado junto à equipe de profissionais que participava das Tardes no Verde durante encontros quinzenais do grupo de estudos. Nesses encontros, ocorridos em turnos não concomitantes às Tardes no Verde, foram tratados diferentes temas relativos à educação de crianças, tendo como ponto de partida das discussões a leitura de trechos selecionados do livro Educação verde, crianças saudáveis: ideias e práticas para incentivar o contato de meninos e meninas com a natureza, de Heike Freire (2013).

\section{O cenário e os participantes}

As Tardes no Verde ocorrem em um pequeno sítio que situa-se no Morro de São Pedro, zona sul de Porto Alegre, o qual se caracteriza por abrigar áreas de nascentes e matas habitadas por uma vasta diversidade de animais, tais como bugios (Alouatta fusca), espécie de macaco considerada em risco de extinção. Com o solo rico em corpos graníticos, o morro foi outrora local de exploração de 
pedreiras. Hoje em dia, junto à mata coexistem áreas de plantios diversificados e de criação de animais.

O sítio possui um hectare de terra e seu terreno é em declive acentuado. $\mathrm{Na}$ extremidade mais elevada do terreno, frente à rua de acesso ao local, encontra-se a casa onde mora o casal Clarissa ${ }^{2}$ e Victor, proprietários do local, e seus três filhos. Para os fundos e a lateral da casa situa-se o Espaço de Integração Timbaúva, ${ }^{3}$ local onde se dão as Tardes no Verde e outras atividades. No espaço há um pequeno parque infantil com uma caixa de areia e tobogã, uma gangorra, balanços confeccionados com pneus, um fogão antigo em desuso e uma pequena casa de brinquedo feita de madeira. Há também uma horta que segue o design proposto pela permacultura, com canteiros em formatos que fogem da linha reta, nos quais se encontram cultivos de várias espécies, tais como alface, rúcula, abóbora, cenoura, temperos e flores de jardim. Próximo à horta fica a cantina onde são preparadas e consumidas as refeições. Aos fundos do terreno, encontram-se dois banheiros externos e um salão construído em formato octogonal com troncos e tábuas de madeira e onde há: sofás, cadeiras, mesas, almofadas, tapetes, instrumentos musicais, uma mesa de pingue-pongue, tintas e lápis de cores, livros e brinquedos, em sua maioria, feitos com madeira e lã, entre outros objetos.

Os participantes das Tardes no Verde, ao passarem pelo portão de entrada do Timbaúva, antes de chegar a essa porção mais central do terreno onde estão as benfeitorias anteriormente descritas, têm de percorrer uma trilha aberta em meio à mata nativa. Como que orientando o caminho, estão dispostas algumas placas de madeira por essa trilha e na parte central do sítio com as seguintes palavras pintadas: portal da criança; afeto; limite (acompanhado do símbolo de coração); autonomia; coragem; confiança; amor; sentidos (ver Figura 1). Alguns vizinhos permitem o acesso a seus terrenos, de modo que é possível ampliar e diversificar os espaços a serem percorridos: matas, riachos, cascatas, açudes, canaviais, bambuzais, plantações, campos e zonas de apiários.

2 Ao longo do texto, faz-se referência aos interlocutores pelo primeiro nome ou pelo cognome com que eram conhecidos, com a concordância dos mesmos.

3 Que de agora em diante será denominado meramente por Timbaúva. 


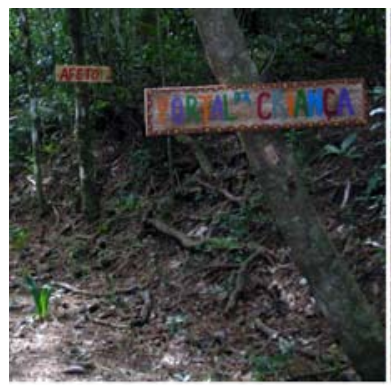

A

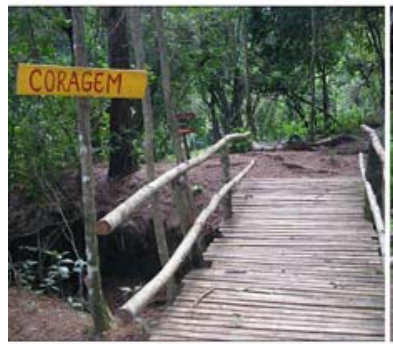

D

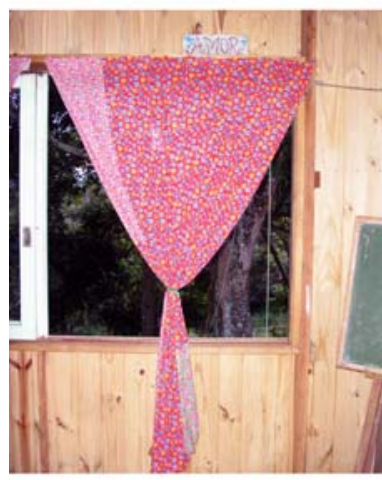

G

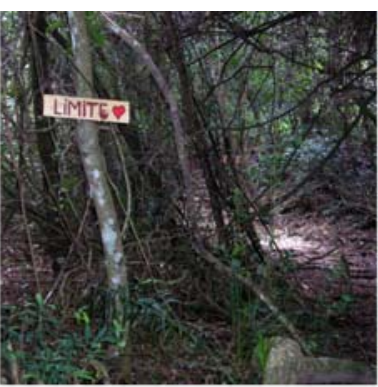

B

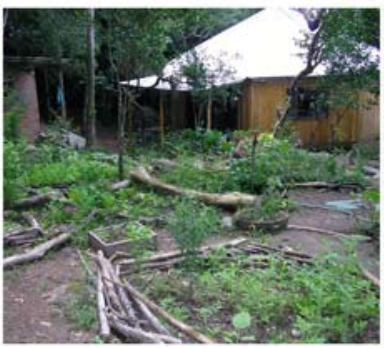

$\mathrm{E}$

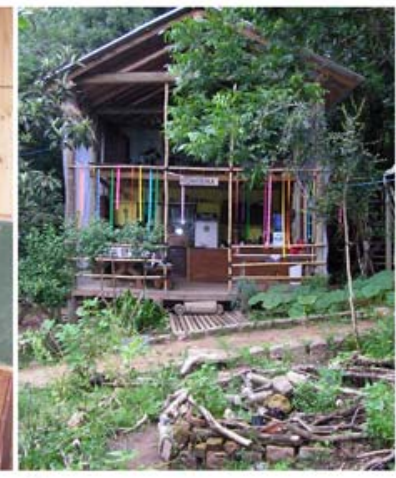

$\mathrm{H}$

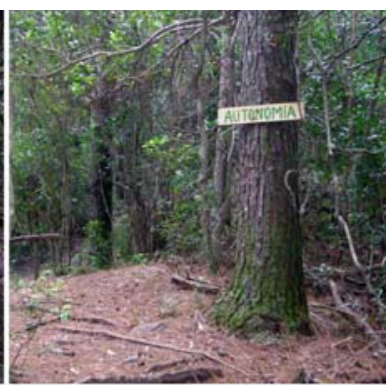

C

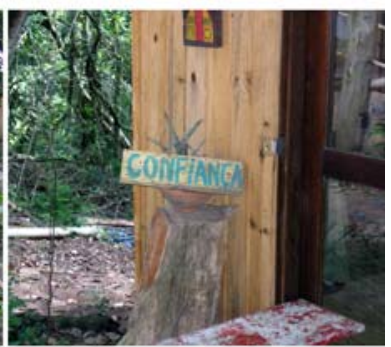

$\mathrm{F}$

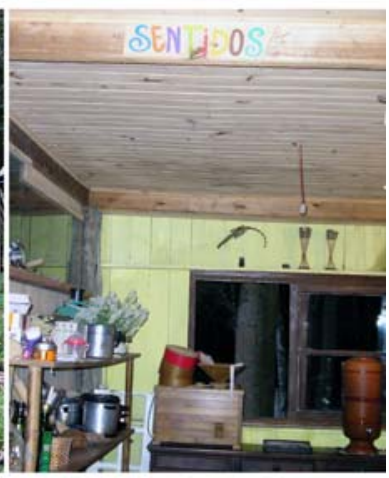

।

Figura 1. Placas para orientação dispostas pelo Timbaúva - quem percorre o caminho de acesso depara-se com diversas placas com as seguintes palavras: "portal da criança" e "afeto" (A), "limite" (B), "autonomia" (C) e "coragem" (D), até chegar à parte central, onde encontra os canteiros, o salão octogonal e os banheiros externos (E). Ali observa placas com os dizeres "confiança" na parte externa (F) e "amor" na parte interna (G) do salão octogonal. Também há nesse espaço uma cantina (H). Na parte interna da mesma, uma placa chama a atenção para os "sentidos" (I) (fotos: Alessandra Rivero Hernandez). 
As pessoas que participam como educadores nas atividades das Tardes no Verde são Victor, Fernanda e Naveen. Victor tem 34 anos, é formado em Letras e lecionou em uma escola que segue a pedagogia Waldorf ${ }^{4}$ em Porto Alegre. Fernanda tem 32 anos, atua também como doula e em projetos de educação popular junto a professores e comunidades quilombolas. Morou durante algum tempo na Ecovila Arca Verde, na cidade de São Francisco de Paula, interior do estado. Naveen tem 29 anos, é formado em geografia e reside na comunidade "alternativa" Osho Rachana, sítio no qual os moradores buscam viver em coletividade, realizando diversas atividades juntos e desenvolvendo práticas de autoconhecimento, bioenergética e meditação. Também colaboram com as Tardes no Verde Clarissa, que prepara o lanche do final da tarde para as crianças e administra o pagamento das mensalidades, e Jaqueline, médica pediátrica e antroposófica, que seguidamente acompanha as atividades com as crianças.

A maioria das crianças que participava das Tardes no Verde provinha de famílias de camada média e média-alta e frequentava no turno da manhã (ou já frequentou) a escola ou um dos jardins de infância, situados em Porto Alegre, que seguem a pedagogia Waldorf. De fato, as Tardes no Verde têm forte inspiração nessa pedagogia na medida em que se busca a interação das crianças com plantas, animais, pedras, brinquedos artesanais, entre outros elementos. Ao longo do trabalho de campo, circularam naquele local um pouco mais de 30 crianças; algumas o frequentaram ao longo de todo o trabalho de campo, enquanto outras foram apenas por duas ou três tardes, um ou dois meses.

4 Elaborada por Rudolf Steiner (1861-1925) com base na antroposofia, concebida esta última por ele a partir do pensamento de Johann Wolfgang Von Goethe (1749-1832) como uma "ciência espiritual" na qual o ser humano é tido como intimamente ligado à natureza e aos seus elementos (minerais, plantas, animais, estrelas, planetas, forças imateriais), de modo a constituírem um organismo único e harmônico. O ser humano (microcosmo) também pode ser considerado uma imagem condensada desse universo (macrocosmo), trazendo em si cada um de seus elementos. Seguindo essa compreensão holística do ser humano, concebido como um ente físico, anímico e espiritual, a pedagogia Waldorf busca possibilitar o desenvolvimento da criança em sua totalidade, cultivando o pensar, o sentir e o querer. Para um aprofundamento sobre o tema, recomenda-se o site da Sociedade Antroposófica do Brasil (http://www.sab.org.br/portal/). 


\section{O percurso de uma tarde}

A primeira ida ao Timbaúva foi numa fria e ventosa tarde de agosto. As crianças corriam por ali perto enquanto Victor e Fernanda tentavam reuni-las ao lado do salão octogonal para fazer uma "trilha", ou seja, percorrer determinado caminho mais ou menos aberto por entre a mata. Havia-se criado uma discussão entre as crianças menores em torno de quem levaria consigo duas varas de bambu. Victor então recolheu as varas e disse-lhes que ninguém as levaria, pois novas varas poderiam ser pegas durante a trilha. Iniciou-se a caminhada atravessando um buraco pelo arame farpado e passando para o terreno do vizinho. Logo em seguida o grupo parou em frente a uma nespereira (Eriobotrya japonica). Algumas crianças subiram na árvore e juntaram algumas nêsperas, que compartilharam com as demais. Após alguns minutos comendo dessas frutas, seguiu-se a caminhada. Logo após, Victor chamou a atenção das crianças para um som de rangido provocado pelo vento ao deparar-se com as folhas dos eucaliptos.

Alguns passos adiante, ele anunciou que o grupo passaria pelos apiários. As crianças reclamaram, dizendo que não queriam ir, pois da vez anterior algumas delas tinham sido picadas. Victor então acalmou as crianças dizendo-lhes que nos dias ventosos as abelhas costumam ficar dentro das caixas. Fernanda pediu a todos para irem em silêncio e apenas depois de passado o apiário comentassem com os demais o que tinham sentido, se tiveram medo ou não.

Passado o apiário, seguiu-se o percurso por entre os bambuzais. O sol não batia tão intensamente por entre os bambus, deixando o ambiente mais fresco e sombrio. A terra estava muito úmida e o terreno era bastante acidentado, repleto de pedras que dificultavam a marcha. Alguns meninos pegaram os bambus que estavam caídos no chão e batiam com força nos que estavam em pé. Para sair dos bambuzais foi preciso escalar algumas pedras que levavam a uma parte mais alta de campo aberto e bem ensolarado. Essa porção mais alta de campo aberto logo sofria uma descida abrupta, chegando aos pés de uma plantação de cana-de-açúcar. Fernanda propôs às crianças que elas descessem até a plantação de cana correndo com os braços abertos e gritando no momento em que percebessem o sopro do vento numa direção favorável, de modo a ajudar na descida. 
Enquanto as crianças desciam correndo algumas vezes, Victor e Fernanda cortavam duas canas e as descascavam para depois separá-las em pedaços. As crianças foram se concentrando ao redor dos dois esperando para ganhar um pedaço de cana. Fernanda disse então que ela daria cana para quem fizesse uma rima. Algumas crianças começaram a criar rimas, enquanto outras decidiram pegar sua porção de cana junto a Victor e assim não ter de fazer uma rima. O grupo permaneceu por ali algum tempo enquanto mascava os pedaços de cana. Após, seguiu-se a caminhada em direção a uma parte um pouco mais afastada do Timbaúva, onde também havia bambuzais.

Já próximo aos bambuzais, Victor propôs que cada uma das crianças escolhesse um bambu para fazer algo: um tacape, um arco com fecha, um cajado ou o que quisessem. As crianças ficaram um bom tempo escolhendo bambus de diferentes tamanhos, alguns eram maiores que as próprias crianças. Depois o grupo retornou ao Timbaúva por outro caminho mais curto, pois já havia passado do horário do lanche. Na chegada ao sítio, Clarissa esperava as crianças com um lanche na cantina: bolinhas de pão integral para untar com manteiga ou mel e canjica.

Depois do lanche as crianças foram para o octógono, trabalhar os bambus. O mais importante, segundo Victor, já havia sido feito: o bambu já tinha escolhido o seu dono. Ele contou que carregava consigo há anos um bambu que encontrou na Rua da Praia, era uma flauta peruana. Pediu para que ficassem de olhos fechados e pensassem na relação de cada um com o seu bambu enquanto tocava a flauta. Depois distribuiu pequenas serras para que as crianças cortassem os bambus. Contudo, os pais começaram a chegar e as crianças foram se despedindo, deixando o trabalho com os bambus para um próximo encontro.

\section{Os elementos dos jogos de linguagem e sua gramática}

Os jogos de linguagem acionados no local buscam constantemente promover a aprendizagem de palavras, sentimentos e percepções em associação a diversos elementos da natureza: bambus, nêsperas, eucaliptos, abelhas, pedras, vento, cana, entre tantos outros. Faz parte desses jogos de linguagem dirigir a atenção das crianças para que vejam determinados aspectos (sons, cheiros, movimentos) que, caso contrário, poderiam passar despercebidos. 
Isso é feito mediante o gesto de apontar enquanto se profere uma palavra, o que o autor denomina de "ensino ostensivo das palavras" (Wittgenstein, 1996, $\S 6^{5}$ ), mas também através do simples emprego de uma palavra para nomear certa situação. Nesse sentido, pode-se pensar a fala de Fernanda, quando as crianças não queriam passar pelo apiário, como uma oportunidade que, antes de propiciar a atenção vigilante do "eu" e a observação das emoções sentidas e da própria subjetividade, possibilitou chamar a atenção das mesmas para o sentimento de medo. ${ }^{6}$ Mesmo porque apenas a partir da aprendizagem da gramática emocional em jogo é que se torna possível enunciar as emoções e trabalhar sobre si. Ou, como diria Wittgenstein (1996, § 580), "um 'processo interno' precisa de critérios externos".

Esses jogos de linguagem são marcados pela lógica da distinção entre natureza e cultura. Em meio aos mesmos, sentimentos como coragem, confiança e amor anunciados nas placas dispostas pelo Timbaúva, entre outras emoções, parecem recobrar também um caráter natural. Essa gramática distintiva rege, por exemplo, diferentes versões do sentimento de medo. De acordo com o livro que fez parte das discussões nos encontros do grupo de estudo, por um lado, o medo é um sentimento natural, que possui um papel relevante na sobrevivência frente a situações de perigo. Esse medo "natural" e "adequado" é evocado em jogos de linguagem que o vinculam a um sistema biológico que cumpre uma função adaptativa dos animais (inclusive os seres humanos) ao meio.

Entretanto, o sentimento de medo adquire outro sentido, tornando-se "descontrolado" e capaz de fazer com que as pessoas fiquem "paralisadas", quando associado a situações e elementos considerados males da civilização, tais como os interesses financeiros e comerciais, os meios de comunicação de massa e o isolamento social experimentado na urbanidade. Também o medo manifesto por uma menina de três anos que participou algumas poucas tardes, ao ver

5 As citações diretas à obra Investigações filosóficas costumam fazer referência não ao número da página, mas ao do parágrafo, em consonância com o modo peculiar como o próprio Wittgenstein a organizou. Seguimos esse padrão no presente artigo; todas as demais citações diretas a expressões e trechos de outros autores foram feitas conforme as normas da revista, que seguem a ABNT.

6 Entretanto, esse momento não ocorreu, as crianças não relataram o que tinham sentido como sugerido nem foram estimuladas novamente a fazê-lo, o grupo simplesmente seguiu adiante pela trilha deixando para trás o apiário. 
algum inseto ou ter de caminhar pela mata foi justificado pelos educadores seguindo essa lógica distintiva. Para eles, o sentimento de medo não era propriamente causado pelos insetos e matas, mas estava relacionado com o fato de ela estar habituada a brincar em um pátio com piso e paredes de concreto.

\section{O trabalho emocional do ambiente preparado}

Durante um dos encontros do grupo de estudos, um dos temas tratado foi o sentimento de tédio como um impulso para a contemplação. Na ocasião, Fernanda comentou que, na tarde anterior, a colocação de uma rede de balanço embaixo da bergamoteira (Citrus deliciosa Ten.) havia possibilitado que algumas das crianças praticassem a observação atenta do seu entorno, atividade essa que ocupou boa parte do turno. Victor falou que embora viesse plantando mais hortaliças e legumes no sítio, estava pensando em plantar mais flores. Em tom jocoso, acrescentou que assim as crianças teriam mais flores para arrancar, 0 que ponderou acabar fazendo parte do processo educativo ali vivenciado.

De fato, não apenas uma rede havia sido colocada embaixo da bergamoteira, mais flores seriam plantadas e placas evocando sentidos e afetos haviam sido dispostas pelo Timbaúva, mas um trabalho contínuo de transformação do espaço estava sendo operado pelos educadores a fim de se produzir, como dizem, um "ambiente preparado". Assim, por exemplo, um caminho por entre a mata foi aberto em direção a uma pequena queda d’água situada próximo ao sítio, de maneira que as crianças poderiam ir ao local até mesmo desacompanhadas de adultos. O local de chegada da "trilha da cascatinha", como fora nomeado, também recebeu algumas preparações que o tornaram mais atrativo. Sacos de areia foram colocados a fim de represar uma quantidade maior de água, de modo a permitir às crianças tomarem banhos em dias quentes. Uma tábua de madeira passou a possibilitar a passagem para o outro lado do córrego e o acesso a uma pequena clareira onde frequentemente as crianças maiores ficavam responsáveis por acender uma fogueira para afugentar os mosquitos. Um par de cadeiras em madeira que permanecia ali mantinha firme o convite para deixar-se estar nesse espaço.

Também dentro do salão octogonal ao longo do tempo foram organizados quatro espaços temáticos bem definidos: um com livros infantis de contos 
clássicos e de lendas, dispostos em prateleiras próximas a um colchão com travesseiros; um com uma cabana feita com cavaletes e panos dentro da qual havia algumas bonecas de pano e bichos de crochê; outro com uma mesa e cadeiras baixas próximas das quais se encontravam lápis de cores, bastões de giz de cera, folhas e argila; e outro com uma grande variedade de instrumentos musicais, tais como uma pequena bateria, violão, pandeiro, kântele, moringa, maracas, pau de chuva, agogô de coco, kalimba, pandeiro, bombo leguero, cajón e violatas feitas por Victor utilizando sucata.

O trabalho emocional do ambiente preparado pode ser mais silencioso, mas certamente não é menos revelador do que aquilo que é verbalizado. Em outras palavras, o ambiente compõe um jogo de linguagem não verbal que possibilita àqueles que nele se encontram aprender sobre as regras operantes. Em sua etnografia junto aos fijianos, Christina Toren (1990) descreve a aprendizagem das crianças a respeito das relações hierárquicas existentes no arquipélago a partir da ocupação do espaço durante o ritual da yaqona, bebida preparada e ingerida em eventos de celebração e de luto. Enquanto os adultos entendem que alguém se senta acima da tanoa (grande tigela onde a yaqona é misturada e servida) porque tem status hierárquico superior, as crianças invertem essa formulação e consideram que alguém tem status superior porque senta acima da tanoa.

Se as crianças fijianas aprendem a lógica hierárquica que rege o sistema de relações ao participarem dessa prática ritual, através da observação da posição ocupada pelas pessoas em torno da tanoa, qual a gramática que as crianças das Tardes no Verde aprendem ao "brincarem livres" em um ambiente preparado com tantas possibilidades? Diferentemente do que na prática ritual referida, não há posições a serem ocupadas e todos transitam pelo ambiente. Nessa movimentação, as crianças aprendem ao longo do tempo a se engajarem ativamente em um conjunto diversificado de práticas, a desenvolverem interesse e gosto por algumas em detrimento de outras, a fazerem escolhas por si mesmas sem que um adulto lhes diga "faça isto, brinque daquilo". A lógica que rege o ambiente preparado é tanto a da escolha individual e da participação ativa, os quais estão interligados ao princípio de liberdade, como a da distinção entre natureza e cultura.

Entretanto, vez por outra outras materialidades atravessavam as fronteiras dessa distinção e entravam em cena, chamando a atenção das crianças. Assim 
ocorreu nas vezes em que as crianças preferiram brincar com as "cartinhas" do Pokémon durante as Tardes no Verde. Nessas ocasiões, os educadores não buscaram coibir a brincadeira, mas incomodados com a situação, não se deixaram atrair pelos comentários das crianças sobre as diferentes criaturas estampadas nas cartas e trataram de envolvê-las em outras brincadeiras, chamando-lhes a atenção para outras materialidades que naquele mesmo momento estavam sendo mobilizadas por outras crianças. Certa tarde, por exemplo, enquanto um grupo de crianças brincava com as cartinhas dentro do octógono, Fernanda sentou-se nas almofadas sobre o tapete junto a uma menina que folheava um livro sobre dinossauros e em voz alta convidou mais de uma vez as demais a saberem mais sobre aqueles animais. Apenas dois meninos de cinco anos foram até ela, enquanto as maiores continuaram envolvidas com as criaturas de jogos de videogame e desenhos animados.

\section{Uma moralidade para ser sentida: a aprendizagem das emoções}

A gramática emocional operada em jogos de linguagem nas Tardes do Verde apresenta dois eixos. Para falar do primeiro, recorremos inicialmente ao sentimento de coragem. O mesmo foi evocado durante uma briga entre dois meninos que ocorreu em uma das Tardes no Verde, descrita brevemente a seguir. Esta briga iniciou-se entre Khalil, de cinco anos e filho de Victor, e outro menino de seis anos aproximadamente, os quais momentos antes brincavam junto a outras crianças. Assim que começou a briga, as demais crianças correram em direção à dupla e formaram um círculo no seu entorno. Victor e Fernanda permaneceram próximos, observando o desenlace da luta. Khalil avançou em direção ao outro menino, que revidou pulando sobre ele, imobilizando-o no chão de terra. Khalil tentou revidar, mas não conseguiu, permanecendo contido por alguns segundos até que o seu adversário resolveu soltá-lo. Ele tentou duas vezes mais, mas sempre com o mesmo fim. Victor então foi em direção aos meninos, parabenizou-os pela "coragem", e disse-lhes que já era hora dos "guerreiros" se cumprimentarem e acabarem com a briga. Os meninos assim fizeram. A tarde transcorreu sem nenhuma outra desavença ou animosidade entre os dois. No final do turno, Fernanda se despediu de Khalil dizendo-lhe que um 
"guerreiro" é antes de tudo um observador e que o outro menino o imobilizou várias vezes porque era um bom observador.

Por certo, o fato de a briga ter se dado sem socos e pontapés, possibilitou aos educadores não intervirem em um primeiro momento. Mas não só por isto a luta não foi contida de imediato. Esta foi uma oportunidade de aprendizagem acerca do que é o sentimento de coragem, não só para os dois meninos que lutavam, mas também para as crianças que presenciavam a briga. Nessa ocasião, Victor poderia também ter nomeado outras emoções que frequentemente se relacionam ao ato de brigar, como, por exemplo, o sentimento de raiva, mas evocou um sentimento tido como virtuoso.

Além do sentimento de coragem, nesse primeiro eixo se destacam emoções tidas como produtivas, que são vinculadas ao engajamento ativo e criativo com o entorno, ao imprimir movimento, e que, do mesmo modo que o ambiente preparado, são regidas pela lógica da escolha individual e da participação ativa. Este é o caso também do sentimento de confiança (em si e nos outros), em oposição ao sentimento de medo, nas situações em que este último é relacionado a um estado de imobilidade e de coerção.

Nesse eixo pode-se destacar também o sentimento de tédio, discutido durante um dos encontros do grupo de estudos como anteriormente mencionado. No referido encontro, considerou-se que hoje em dia as crianças se sentem entediadas mais frequentemente. $\mathrm{O}$ tédio foi associado ao excesso de tempo livre passado pela criança dentro de casa e à redução do número de filhos, e a decorrente menor interação com outras crianças. Embora o sentimento de tédio se configure como "uma forma de relação com o tempo em que este é subjetivamente vivenciado como imóvel” (Rezende; Coelho, 2010, p. 68) e, nesse sentido, considerado indesejável haja vista a lógica vigente, o mesmo não foi abordado como um sentimento que deva ser afastado. Pois ao mesmo tempo ele é tido também como um sentimento criativo, ao qual se segue um momento de intensa atividade. Dessa forma, ponderou-se que adultos não deveriam sugerir atividades para uma criança que manifeste estar chateada, sem saber o que fazer, mas sim deixá-la descobrir por conta própria com o que brincar.

Um caráter moral está constantemente implicado na gramática emocional vigente. Trata-se de uma moralidade que não é transmitida ou ensinada, mas sim de um conjunto de valores e regras de ação que devem ser sentidos e 
incorporados pela criança a partir dos jogos de linguagem. Pois o que está em cena não é uma "moral orientada para o código", que é submetida às crianças por autoridades, mas uma dimensão da "moral orientada para a ética" (Foucault, 1984, p. 30). Nesse sentido, o que está em vista para os interlocutores é a constituição do sujeito moral, capaz de conduzir a si mesmo tendo como referência os elementos prescritivos que constituem um determinado código moral.

Como parte dessa aprendizagem, os educadores buscam dirigir a atenção das crianças para as ações dos outros, como aponta Fernanda ao salientar a capacidade de observação do antagonista enquanto qualidade fundamental de um guerreiro. Um aspecto relevante da experiência emocional nas sociedades ocidentais modernas, como sugerem Rezende e Coelho (2010), é a preocupação com o controle dos sentimentos. A partir do trabalho de Norbert Elias sobre o processo civilizador na Europa, as autoras apontam para o ajuste do próprio comportamento por meio da observação do comportamento dos outros em decorrência do aumento da interdependência entre as pessoas no início do século XIX. O autocontrole das emoções e do comportamento em função dos outros levou, conforme Elias, a uma forma calculada de agir e de lidar com a conduta dos outros em um processo de racionalização e de psicologização dos comportamentos.

\section{A sacralidade da natureza: aprendendo uma forma de vida}

Retomando a ocasião da passagem pelo apiário, Victor buscou tranquilizar as crianças falando-lhes sobre a conduta das abelhas de ficar dentro das caixas em dias ventosos, como mencionado anteriormente. O sentimento de medo, portanto, não faria sentido mediante esse conhecimento. Em sua pesquisa etnográfica sobre o tornar-se adulto na pequena cidade paraibana de Catingueira, Flávia Pires (2007) observou que esse processo implicava tornar-se uma pessoa religiosa. Como parte do processo de se tornar religioso, a autora aponta para a mudança da compreensão do que são os mal-assombros. Enquanto para os adultos os mal-assombros eram as almas dos mortos, para as crianças era tudo aquilo que faz medo, constituindo-se em um grande número de entidades. À medida que as crianças iam crescendo, a variedade de entidades plausíveis 
de serem consideradas mal-assombro ia se restringindo à alma dos mortos. Com base na moral cristã, as demais entidades deixaram de ser consideradas reais, e dessa forma não mais apresentaram perigo.

E no caso das Tardes no Verde, deixar de sentir medo a partir do conhecimento sobre a interação entre o vento e o comportamento das abelhas está implicado com que forma de vida? Toda a multiplicidade de atividades operadas no espaço busca sensibilizar as crianças para uma forma particular de habitar o mundo enquanto "sujeitos modernos ecologicamente orientados" (Carvalho; Steil, 2013, p. 107). Como parte dessa sensibilização ecológica, as crianças aprendem também sobre o sentimento de sacralidade em relação à natureza.

Ao analisarem o valor moral atribuído à natureza na contemporaneidade, Isabel Carvalho e Carlos Steil (2013) apontam para a ocorrência de um duplo movimento, tanto de naturalização do humano (reinserindo-o no mundo natural) como de sacralização da natureza, esta última implicada com a identificação da natureza como fonte de referência ética e estética para o comportamento humano. Embora o conservacionismo norte-americano do século XIX esteja informando na atualidade a noção de natureza como sendo boa, bela, autêntica e transcendente, os autores consideram que a emergência das espiritualidades do self transformou em parte a noção de natureza, elevando-a à condição de sagrada (Carvalho; Steil, 2013, p. 113): “O ambiente assume [...] um sentido divino, na medida em que 'Deus' não apenas o habita, mas materializa-se nele, como ideal de perfeição moral, fonte de bem-estar e padrão estético para a ação humana."

O sentimento de sacralidade frente à natureza foi evocado durante a festa de comemoração do equinócio de outono junto a alguns pais e crianças que participavam das Tardes no Verde. Uma das atividades propostas na ocasião foi a realização de uma trilha até o "lugar sagrado", situado não muito longe do sítio. Antes de começar a caminhada, Victor reuniu todos os presentes e fez duas perguntas que poderiam ser respondidas na chegada ao ponto final da trilha. Uma das perguntas era por que aquele lugar era sagrado e, a outra, quem estava segurando quem. Os participantes caminharam por uma trilha por entre a mata até se depararem em meio a uma clareira com uma pedra de tamanho colossal, em cima da qual havia, como que montada sobre a mesma, uma grande figueira. Suas potentes raízes contornavam a pedra, chegando até 
o solo. Durante o tempo de permanência naquele espaço, alguns adultos discutiam como aquilo teria ocorrido, outros tiravam fotos ou, ainda, escalavam a pedra. Já as crianças, todas, se dedicaram a escalar a pedra.

Nessa ocasião, a figueira sobre a pedra foi associada à palavra "sagrado" e à ideia de uma relação de cooperação e de amparo mútuo, uma vez que a figueira sustentava a pedra, que assim não tinha como sair rodando pelo terreno em declive, ao passo em que a pedra sustentava a figueira em pé. De um modo mais amplo, o jogo de linguagem utilizado falou da coesão e do convívio harmonioso enquanto valores éticos a serem aprendidos a partir da natureza.

O sentimento de sacralidade, que diz respeito ao segundo eixo da gramática emocional, se vincula à lógica da distinção entre natureza e cultura anteriormente referida e rege sentimentos que informam como os distintos entes considerados como pertencentes ao domínio da natureza (incluindo os humanos) devem se relacionar entre si. Nesse eixo se sobressaem emoções que, como a sacralidade e o amor, evocam relações de concordância, em oposição a emoções que rementem à discórdia e à ruptura dessas relações, como é o caso da raiva e do ódio.

Embora tomar a natureza como sagrada possa levar a pensar que a mesma não deve ser tocada ou afetada de algum modo, não é assim que esse sentimento é praticado durante as Tardes no Verde. Ali, as crianças aprendem que a sacralidade da natureza não implica simplesmente contemplá-la. Assim, por exemplo, durante a primavera, quando o Timbaúva ficou inundado de flores de abóbora (Cucurbita sp.), de capuchinha (Tropaeolum majus) e de manacá (Brunfelsia sp.), os educadores decidiram não mais solicitar às crianças, frente à insistência das mesmas, para que não as arrancassem. Ainda nessa época do ano, as crianças se divertiram colocando em tigelas revestidas com folhas algumas das lagartas pretas com listras amarelas que surgiam por entre as folhas dos manacás, retirando-as do habitat onde vivem e se alimentam até se transformarem nas belas borboletas-do-manacá (Methona themisto). É bem verdade que a maioria das lagartas retornou ao seu local de origem após as brincadeiras, muitas vezes graças ao pedido dos educadores.

Desse modo, as crianças conseguiram afetar não apenas a natureza, mas em alguma medida alguns princípios das práticas ecológicas como o de preservação ambiental e de não direito de reduzir a biodiversidade. Mas insistir para que as crianças não afetassem de modo intenso as flores e as lagartas seria, na 
perspectiva da proposta pedagógica em foco, de forte caráter romântico, como pedir-lhes que se tornassem indiferentes às cores, odores e formatos das flores, ou, ainda, aos fios de seda produzidos pelas lagartas ao se deslocarem pelas folhas. É preciso ter em conta que esse processo educativo se diferencia daquele da educação tradicional no qual se busca meramente despertar nas crianças uma consciência ecológica e a preocupação para com o meio ambiente. Desse modo, o processo de aprendizagem passa por essa licença dada às crianças em um primeiro momento para que arranquem flores, retirem as lagartas do seu habitat e acessem as práticas por meio das quais educam sua atenção. Em seguida, já em meio a flores, lagartas e palavras (dentre as quais a enunciação de emoções tem um papel relevante), elas aprendem os valores e regras associados essa forma de vida.

\section{Sobre seguir uma gramática emocional}

Como anteriormente abordado, o conceito de jogos de linguagem implica analisar a linguagem em seu contexto de uso, em meio ao qual o emprego das palavras tem regras definidas. Contudo, como observa Veena Das (2008) a partir do pensamento de Wittgenstein, fazer com que uma criança concorde com uma forma de vida particular não significa obedecer a essas regras de modo cego e sem vacilação. Tampouco requer que a criança produza a mesma resposta que o educador.

Nesse sentido, é descrita a seguir uma situação etnográfica ocorrida, depois de passados alguns meses de trabalho de campo, durante uma trilha. Desde o começo da caminhada, três meninos, de nove e dez anos, foram delongando seu andar, ficando mais para o final da fila. Ao atravessar a rua asfaltada que fica em frente ao sítio, o trio encontrou uma cobra com uns 40 centímetros de comprimento, morta aparentemente há pouco tempo. Eles a mostraram aos demais, queriam saber de qual espécie seria, abriam-lhe a boca para observar seus dentes e língua, alguns a colocavam no pescoço como se fosse um colar, outros tentaram dar nós em seu corpo. A atenção desses três meninos estava direcionada para a cobra. Ao entrarmos na mata, Victor e Naveen reuniram todas as crianças e pediram para que as mesmas prestassem atenção às orientações que iriam dar a respeito do caminho. Os três meninos seguiram conversando 
entre si a respeito da cobra. Os educadores solicitaram novamente a atenção de todos, mas seus pedidos não surtiram efeito. Victor então pediu ao menino que segurava a cobra que lhe a entregasse, mas diferentemente do que em outras oportunidades não aproveitou o encontro com a cobra para falar sobre suas características, se era venenosa ou não ou qual sua espécie. Certamente, seu ânimo não estava afetado apenas pelo encontro dos meninos com a cobra, mas também pelo acontecido na semana anterior: alguém tinha jogado algo (talvez uma fralda, ou quem sabe galhos ou pedras) nas privadas dos dois banheiros externos, obstruindo-as. Já em posse do animal, ele então a jogou em direção ao mato dizendo que a cobra havia vindo da natureza e para lá voltaria. O menino que entregou a cobra a Victor fez uma expressão de choro assim que o animal foi lançado ao mato, mas em poucos segundos, ao invés de chorar, começou a arrancar as folhas de arbustos próximos a ele, aos gritos de "eu odeio a natureza!". Os educadores então orientaram as crianças a atentarem para os galhos secos que iriam encontrar durante a trilha. Durante a caminhada, o trio foi pisando com força e quebrando os galhos secos sobre o chão. No retorno para o Timbaúva, à altura de uma clareira por entre o pinhal, os educadores pediram às crianças que parassem. Elas se sentaram em pedras e troncos, enquanto os educadores em pé relembraram o incidente das privadas obstruídas. Quando algumas das crianças começaram a falar que não tinham sido elas, os educadores pediram para que não falassem que não tinham sido elas, ou mesmo que delatassem os responsáveis, pois esses sabiam o que tinham feito. Seu pedido foi que os culpados refletissem a respeito de sua ação.

Retornando à discussão apresentada por Veena Das (2008), a antropóloga indiana afirma que a linguagem é governada por regras, mas que as regras não cobrem toda e qualquer circunstância possível, de modo que sempre há uma brecha de manobra e negociação entre a regra e sua aplicação. As regras, portanto, mais que regulatórias, são constitutivas, como aponta Wittgenstein (1996, § 85):

Uma regra está aí como uma placa de orientação. Ela não deixa em aberto nenhuma dúvida sobre o caminho que devo seguir? Ela mostra em que direção devo ir quando passo por ela: se seguindo a estrada, ou a caminho do campo, ou pelo meio do pasto? Mas onde está dito em qual sentido eu devo segui-la, se na direção da mão ou (por exemplo) na direção oposta? 
Inicialmente pode parecer que a gramática emocional tenha sido, mesmo que momentaneamente, esquecida ou contestada quando se afirma odiar a natureza. Entretanto, é justamente a aprendizagem da lógica atuante no local que tornou interessante usá-la nesse contexto para discordar e rebelar-se contra a imposição do término à brincadeira com a cobra. Pois, como Das argumenta, concordar com uma forma de vida (e a brincadeira com a cobra em si já fazia parte de uma forma de vida ecologicamente orientada) está longe de ser um processo de aculturação ou transmissão de regras de maneira mecânica ou sem transformações e contestações, tratando-se de um processo muito mais complexo, no qual o "aprendente" pode até mesmo se opor às regras, ainda que momentaneamente.

\section{Considerações finais}

Apesar das propostas de educação engajada surgirem a partir da crítica à transmissão de conhecimentos, não significa que não haja um conteúdo a ser aprendido pelas crianças ao "brincarem livres" pelo Timbaúva. Como discutido ao longo deste trabalho, ao participarem em atividades em meio a árvores, flores, bambus, abelhas, lagartas, trilhas, as crianças aprendem uma forma de vida ecologicamente orientada. Contudo, não se trata simplesmente de uma aprendizagem decorrente de se estar na natureza, mas sim de um certo modo de estar e se relacionar com a natureza que é conformado a partir dos jogos de linguagem.

As reflexões apresentadas neste artigo foram elaboradas a partir do trabalho de campo realizado em um pequeno sítio localizado na zona sul de Porto Alegre. Contudo, a gramática emocional "alternativa" não está circunscrita ao local ou àqueles que dele participam. Ela é difundida a partir de diferentes meios de comunicação (e o livro utilizado pelos educadores, editado originalmente na Espanha e traduzido em seis idiomas, é um exemplo disso) de modo a constituir uma "comunidade de sentimentos". Essa expressão foi criada por Arjun Appadurai (1990) para se referir a grupos que, embora nunca tenham se conhecido, começam a imaginar e a sentir coisas em conjunto. Para o antropólogo indiano, esse fenômeno tornou-se possível, em parte, mediante os meios de comunicação de massa. 
Ao longo do texto, argumentou-se que dois eixos constituem uma gramática emocional vinculada ao individualismo romântico. Um diz respeito à lógica da escolha individual e da participação ativa, desdobramentos do princípio de liberdade, e rege emoções associadas ao engajamento ativo e criativo. O outro eixo se vincula à lógica da distinção entre natureza e cultura e rege sentimentos que informam como os distintos entes considerados como pertencentes ao domínio totalizante da natureza devem se relacionar entre si.

Essa concepção de natureza, apesar de ser holista, apresenta-se de modo paradoxal. Por um lado, se aproxima do princípio de igualdade ao estender a capacidade de agência também aos não humanos, como quando Victor diz às crianças que "o bambu já tinha escolhido o seu dono", ou quando o Timbaúva é referido como um local "terapêutico". Por outro, aproxima-se do princípio de hierarquia, próprio da configuração totalizante, ao diferenciar os humanos como sendo os únicos seres da natureza aptos a exercer a liberdade. Como atenta Duarte (2004), o pensamento romântico enquanto reação ao Iluminismo opera permanentemente em tensão com este, ora afastando-se e enfatizando o princípio de hierarquia, ora acercando-se e acentuando o principio de igualdade.

Ainda, embora essa gramática emocional "alternativa" se paute na lógica da escolha individual e da participação ativa, ficam claras nos exemplos etnográficos apresentados ao longo do artigo as ambiguidades presentes nesse regime de discursos e práticas. Pois apesar da realização de escolhas, da intensa movimentação e atividades das crianças estarem recobertas de um caráter de espontaneidade, todo tempo o "ambiente preparado" e os educadores estão incitando essas ações. Exemplo disso é quando os educadores definem uma trilha a ser percorrida, realizam atividade guiada com os bambus, determinam o término de uma briga, selecionam quais objetos irão compor o ambiente. Essas ambiguidades levam a pensar no Indivíduo não como uma entidade pré-social ou livre de obrigações (o que se relaciona com a tensão entre indivíduo e sociedade, tão presente no campo empírico investigado), mas como efeito das práticas sociais. 


\section{Referências}

APPADURAI, A. Topographies of the self: praise and emotion in Hindu India. In: LUTZ, C.; ABU-LUGHOD, L. (ed.). Language and the politics of emotion. Cambridge: Cambridge University Press, 1990. p. 92-112.

BATESON, G. Pasos hacia una ecología de la mente: una aproximación revolucionaria a la autocomprensión del hombre. Buenos Aires: Carlos Lohlé, 1991.

CADAVID, J. J. B. Introducción: esbozo del pensamiento de Wittgenstein. In: CADAVID, J. J. B. El pensamiento de L. Wittgenstein. Bogotá: Editorial Unibiblos, 2001. p. 11-34.

CARVALHO, I. C. de M. A invenção do sujeito ecológico: sentidos e trajetórias em educação ambiental. 2001. Tese (Doutorado em Educação) - Faculdade de Educação, Universidade Federal do Rio Grande do Sul, Porto Alegre, 2001.

CARVALHO, I. C. de M.; STEIL, C. A. Natureza e imaginação: o deus da ecologia no horizonte moral do ambientalismo. Ambiente e Sociedade, São Paulo, v. 16, n. 4, p. 103120, 2013.

CAVELL, S. The claim of reason: Wittgenstein, skepticism, morality, and tragedy. New York: Oxford University Press, 1999.

DAS, V. Wittgenstein y la antropología. In: ORTEGA, F. (ed.). Veena Das: sujetos del dolor, agentes de la dignidade. Bogotá: Universidad Nacional de Colombia, Facultad de Ciencias Humanas: Pontificia Universidad Javeriana, Instituto Pensar, 2008. p. 295-341.

DUARTE, L. F. D. A pulsão romântica e as ciências humanas no Ocidente. Revista Brasileira de Ciências Sociais, v. 19, n. 55, p. 5-18, 2004.

DUMONT, L. Homo hierarchicus: ensayo sobre el sistema de castas. Madrid: Aguilar, 1970.

DUMONT, L. O individualismo: uma perspectiva antropológica da ideologia moderna. Rio de Janeiro: Rocco, 1985.

FOUCAULT, M. História da sexualidade II: o uso dos prazeres. Rio de Janeiro: Graal, 1984.

FREIRE, H. Educação verde, crianças saudáveis: ideias e práticas para incentivar o contato de meninos e meninas com a natureza. São Paulo: Cultrix, 2013.

ORTEGA, F. Rehabitar la cotidianidad. In: ORTEGA, F. (ed.). Veena Das: sujetos del dolor, agentes de la dignidade. Bogotá: Universidad Nacional de Colombia, Facultad de Ciencias Humanas: Pontificia Universidad Javeriana, Instituto Pensar, 2008. p. 15-69. 
PIRES, F. F. Quem tem medo de mal-assombro?: religião e infância no semiárido nordestino. 2007. Tese (Doutorado em Antropologia Social) - Museu Nacional, Universidade Federal do Rio de Janeiro, Rio de Janeiro, 2007.

REZENDE, C. B. Emoção, corpo e moral em grupos de gestante. Revista Brasileira de Sociologia da Emoção, v. 11, n. 33, p. 830-849, 2012.

REZENDE, C. B.; COELHO, M. C. Antropologia das emoções. Rio de Janeiro: Editora FGV, 2010.

TOREN, C. Making sense of hierarchy: cognition as social process in Fiji. London: The Athlone Press, 1990.

WITTGENSTEIN, L. Investigações filosóficas. São Paulo: Nova Cultural, 1996.

Recebido: 25/05/2018 Aceito: 05/02/2019 | Received:5/25/2018 Accepted: 2/5/2019 